Supplement of

\title{
Mapping gaseous dimethylamine, trimethylamine, ammonia, and their particulate counterparts in marine atmospheres of China's marginal seas - Part 2: Spatiotemporal heterogeneity, causes, and hypothesis
}

\section{Yating Gao et al.}

Correspondence to: Xiaohong Yao (xhyao@ouc.edu.cn)

The copyright of individual parts of the supplement might differ from the article licence. 

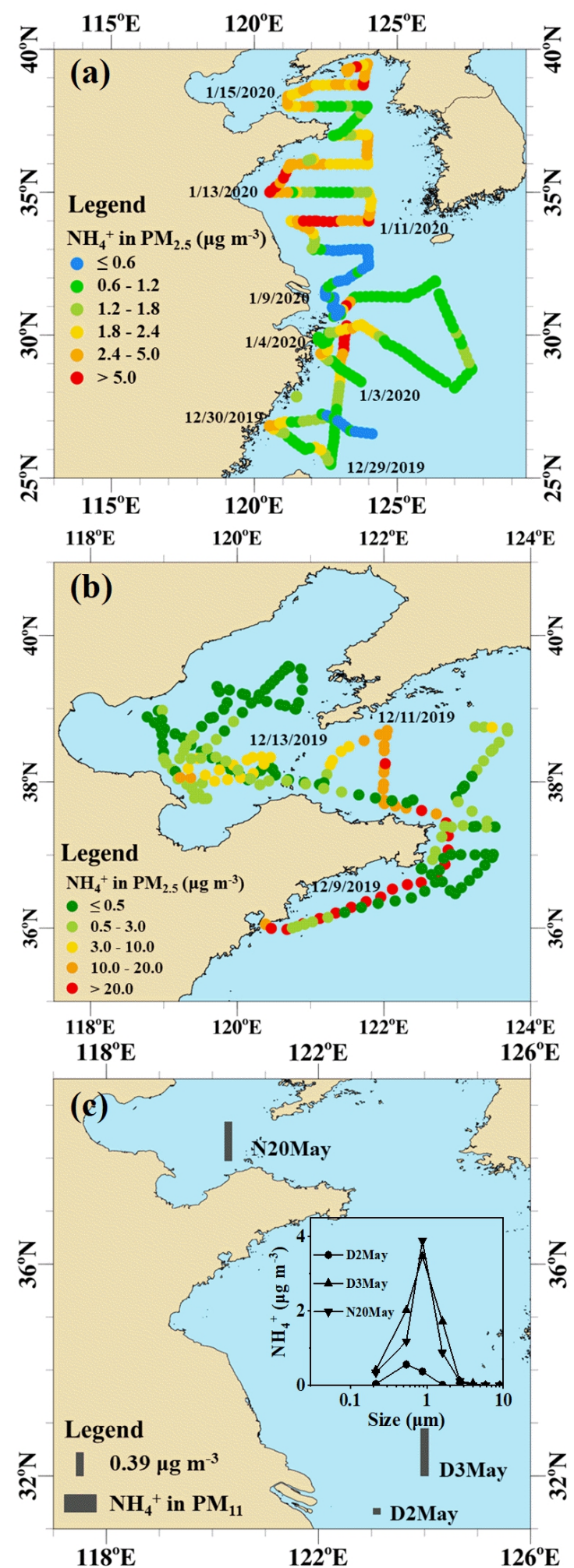

Figure S1: Map of particulate $\mathrm{NH}_{4}{ }^{+}$in marine atmospheres during three campaigns: (a) Campaign $\mathrm{B}$, (b)

Campaign A, and (c) Campaign $\mathrm{C}$, size distributions of particulate $\mathrm{NH}_{4}{ }^{+}$was superimposed in (c). D2May, D3May, N20May represent samples collected in the daytime on May 2 and 3, 2012, and in the nighttime on May 20, 2012, respectively. 


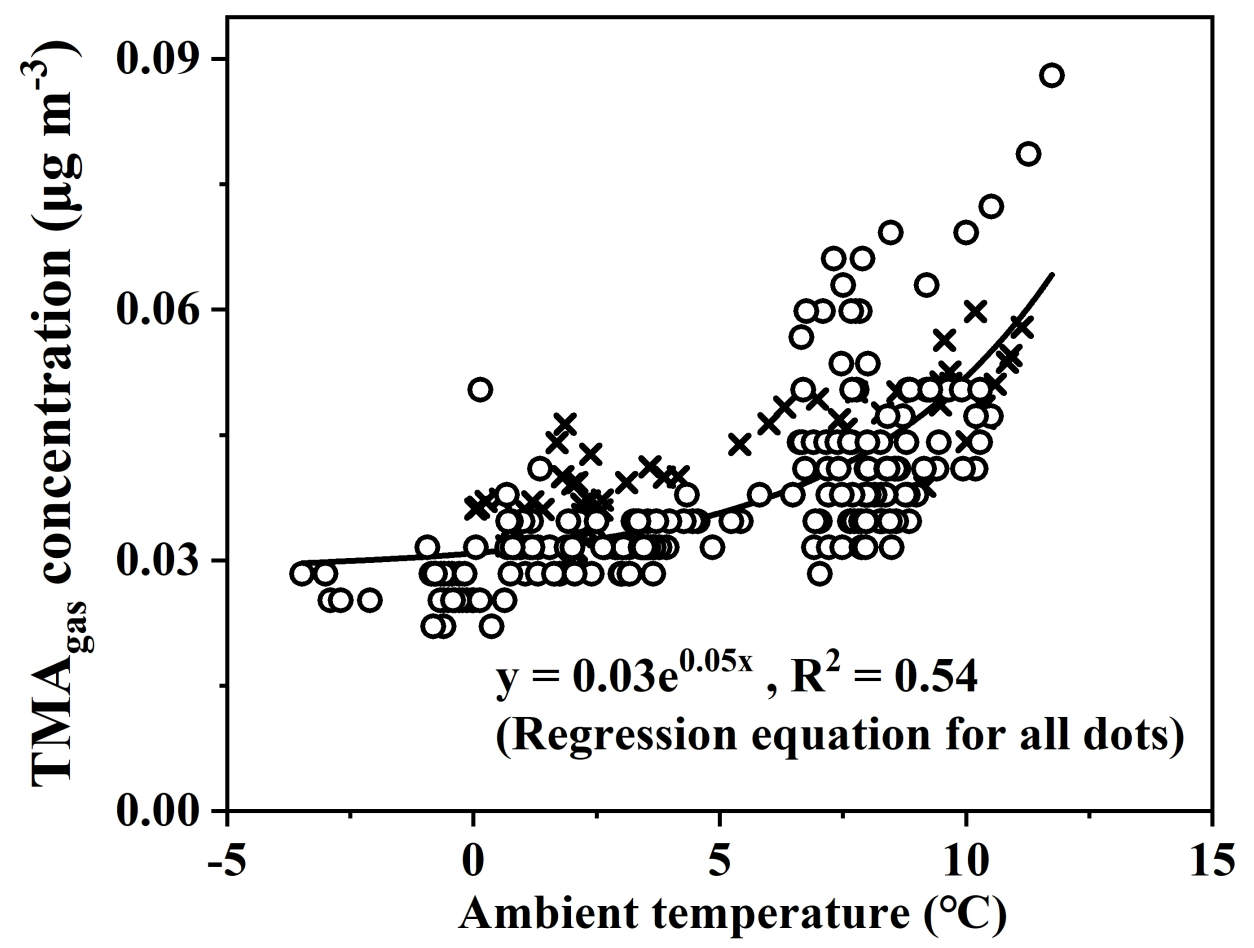

Figure S2: Correlation of TMAgas with ambient temperature (open circle and cross represent data collected in Campaign B and a particular period of Campaign A, respectively). 

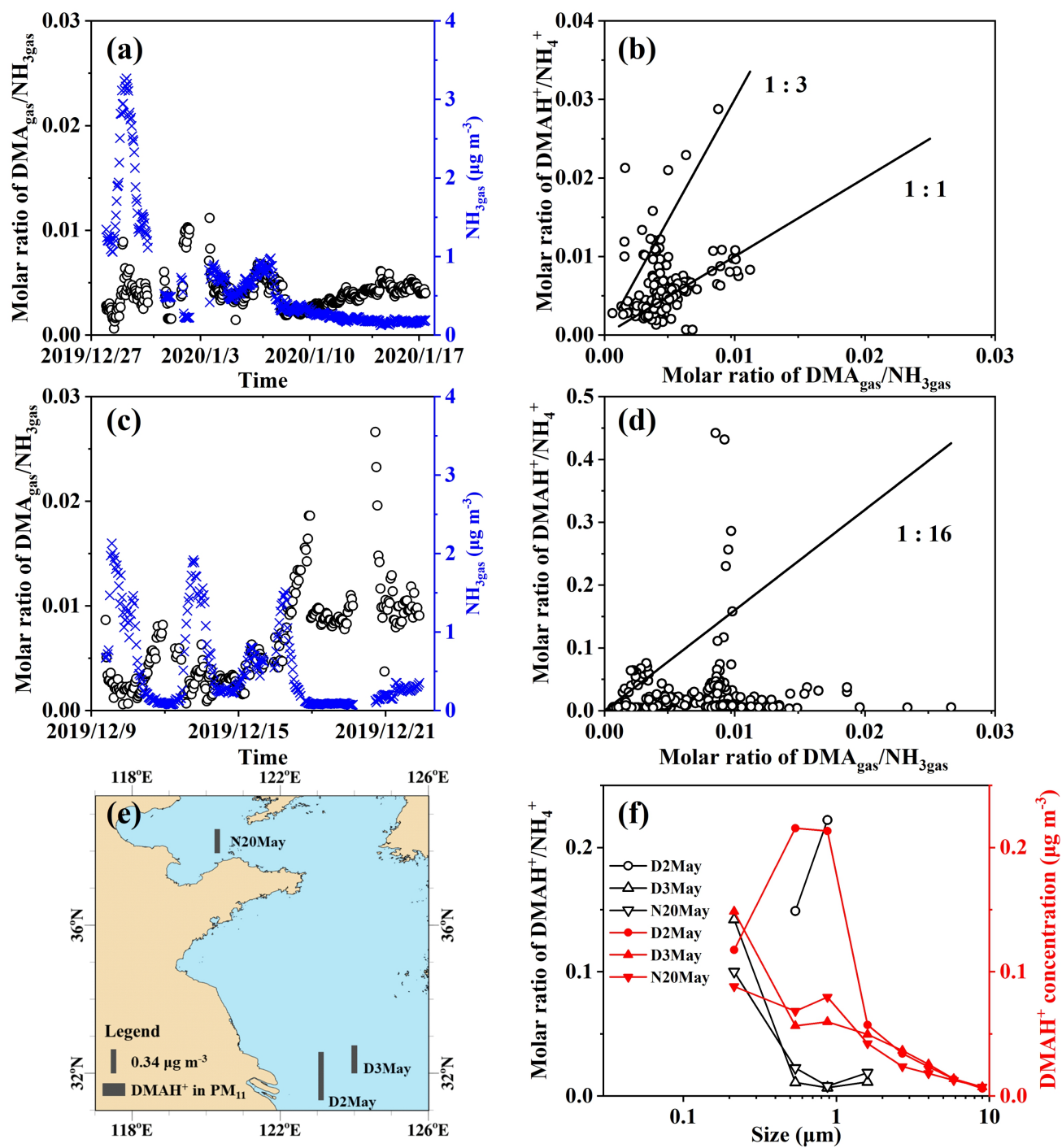

Figure S3: Time series of molar ratios of $\mathrm{DMA} \mathrm{A}_{\mathrm{gas}} / \mathrm{NH}_{3 \mathrm{gas}}$ (a) and (c) in Campaign $\mathrm{B}$ and $\mathrm{A}$; correlation between DMAgas $/ \mathrm{NH}_{3 \text { gas }}$ and DMAH ${ }^{+} / \mathrm{NH}_{4}{ }^{+}(\mathrm{b})$ and (d) in Campaign $\mathrm{B}$ and $\mathrm{A}$; map of particulate DMAH $\mathrm{DM}^{+}$(e) and size distributions of $\mathrm{DMAH}^{+} / \mathrm{NH}_{4}{ }^{+}$and mass concentrations of $\mathrm{DMAH}^{+}$; (f) in $\mathrm{Campaign} \mathrm{C}$ 

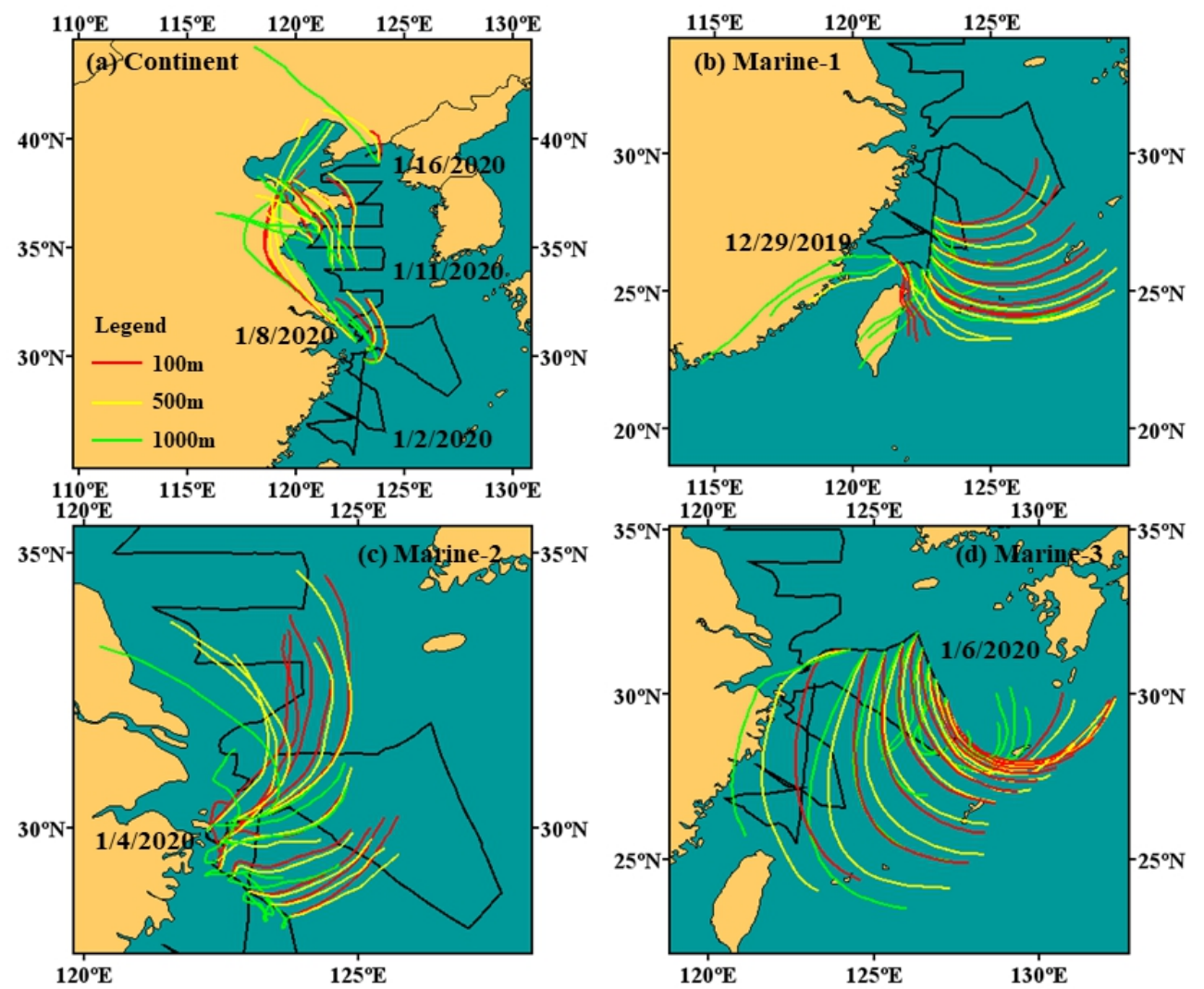

Figure S4: The 24-hr air mass backward trajectories at $100 \mathrm{~m}, 500 \mathrm{~m}$, and $1000 \mathrm{~m}$ above sea level during Campaign B corresponding to the samples (a) when the concentration of $\mathrm{NH}_{4}^{+}$exceeded $5 \mu \mathrm{g} \mathrm{m}^{-3}$, (b)

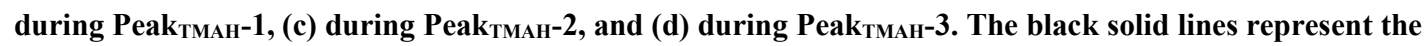
campaign cruises. 


\section{Equations S1-4}

$K_{H}(D M A)=a D M A / p D M A=m D M A \cdot \gamma_{D M A} / p D M A$

$K_{b}(D M A)=\left(a D M A H^{+} \cdot a O H^{-}\right) /\left(a D M A \cdot a H_{2} O\right)$

$=\left(m D M A H^{+} \cdot m O H^{-} / m D M A\right) \times\left(\gamma_{D M A H^{+}} \cdot \gamma_{O H^{-}} /\left(\gamma_{D M A} \cdot a H_{2} O\right)\right)$

$(\mathrm{S} 2)$

$m D M A_{(e f f .)}=m D M A+m D M A H^{+}=p D M A \cdot K_{H}(D M A) \cdot\left[1+K_{b}(D M A) / m O H^{-}\right]$

${ }^{(e f f .)} K_{H}(D M A)=m D M A(e f f.) / p D M A=K_{H}(D M A) \cdot\left[1+K_{b}(D M A) / m O H^{-}\right]$

where ${ }^{\text {(eff.) }} \mathrm{K}_{H}$ (DMA) is the effective Henry's Law constant of DMA, including the undissociated amine and aminium cation. $\mathrm{K}_{\mathrm{H}}$ is the Henry's Law constant $\left(\mathrm{mol} \mathrm{kg}{ }^{-1} \mathrm{~atm}^{-1}\right), \mathrm{K}_{\mathrm{b}}$ is the base dissociation constant $\left(\mathrm{mol} \mathrm{kg}^{-1}\right)$, the prefix $\mathrm{m}$ indicates molality $\left(\mathrm{mol} \mathrm{kg}^{-1}\right)$, and $\mathrm{p}$ is the partial pressure (atm).

According to the Eqs. S1-4, the effective Henry's Law constant is a function of $\mathrm{pH}$ and temperature. The same is true for TMA and $\mathrm{NH}_{3}$. 